


\title{
MELISANDRA Y LAS AMAZONAS: UTOPISMO FEMINISTA EN WASLALA DE GIOCONDA BELLI
}

\author{
MELISANDRA AND THE AMAZONS: FEMINIST UTOPIANISM IN \\ WASLALA BY GIOCONDA BELLI
}

Josefa Lago Graña

\begin{abstract}
RESUMEN
La novela Waslala (1996) de la nicaragüense Gioconda Belli explora la preocupación humana por encontrar un "lugar feliz" o en su defecto crear una sociedad perfecta según el modelo de la Utopía (1516) de Tomás Moro. En Waslala, una comunidad secreta y cerrada, escondida en la selva de Centroamérica, el proyecto utópico fracasa cuando la práctica de gobierno y manejo del poder crea discordia entre los miembros de la comunidad y destruye sus ideales de armonía, igualdad y justicia sobre la cual la comunidad fuera fundada. Sin embargo, la novela de Belli ofrece propuestas alternativas a la utopía concebida por la visión masculina, esta vez alineadas de acuerdo a una visión feminista. Su propuesta utópica pone la construcción de comunidad en el centro y a las mujeres al frente del proyecto nacional. La novela presenta a cuatro mujeres que con su iniciativa y liderazgo consiguen generar espacios seguros para las víctimas del caos social creado por los conflictos bélicos y la avaricia humana. La fuerza de estas mujeres recuerda a las sociedades matriarcales de las amazonas, un mito griego que representa los peligros del poder femenino con su amenaza de desestabilizar la sociedad patriarcal.

Palabras clave: utopismo, feminismo, Gioconda Belli, Nicaragua, Waslala.
\end{abstract}

\begin{abstract}
The novel Waslala (1996) by Nicaraguan writer Gioconda Belli explores the timeless human concern to find a "happy place" or instead to create a perfect society following the model established by Thomas More in Utopia (1516). In Waslala, a secret, closed community hidden in the Central American jungle, the utopian project fails when the practice of government and the use of power bring discord among the founding fathers of the community and destroy their ideals of harmony, equality and justice the community was based upon. However, Belli's novel offers an alternative model to the male utopia, by incorporating a feminist vision to the formation of a better, more just society. Her utopian proposal places community building at the center and women at the front of the national project. The novel features four women whose leadership and initiative contribute to the opening of safe spaces for victims of social chaos created by armed conflicts and human greed. The strength of these women brings to mind the matriarchal societies of the Amazons, a Greek myth depicting the dangers of female power with its threat of destabilizing the patriarchal society. Keywords: utopianism, feminism, Gioconda Belli, Nicaragua, Waslala.
\end{abstract}

Dra. Josefa Lago Graña. University of Puget Sound. Profesora de Estudios Hispánicos. Departamento de Lenguas Extranjeras y Literatura. Estados Unidos.

Correo electrónico: jlago@pugetsound.edu

Recepción: 02- 08- 2015

Aceptación: 03- 09- 2015 
La búsqueda del lugar feliz ha sido una constante preocupación humana. Desde La República de Platón, los filósofos y pensadores han tratado de imaginar una sociedad ideal, reinventada y re-imaginada a través de la historia, tanto en ficción como en comunidades intencionales. La palabra "utopía" viene del griego "eu-topos" (el "buen lugar") y "ou-topos" (el "no lugar"). De la combinación de ambos términos obtenemos el significado completo del concepto como un lugar ideal que no existe o no puede encontrarse. La RAE define "utopía" como un "plan, proyecto, doctrina o sistema optimista que aparece como irrealizable en el momento de su formulación" (n. p.) mientras que para Louis Marin es un espacio liminar que conecta lo posible a lo imposible, como el horizonte que hace que lo invisible se acerque a lo finito (1993, p. 411).

El texto Utopía (1516) de Tomás Moro adopta el término griego para darle nombre a una isla donde existe una comunidad pacífica que practica la propiedad común de los bienes y escoge a sus gobernantes y legisladores mediante el voto popular. Moro contrasta esta comunidad con las sociedades contemporáneas europeas de la época, en particular aspectos filosóficos, económicos y políticos de la Inglaterra del momento. Según Beatriz Pastor, la obra de Moro "es la primera recodificación moderna de una propensión utópica que se manifiesta desde la antigüedad clásica y durante toda la Edad Media en una serie interminable de formulaciones heterogéneas de signo social o religioso" (1996, p. 24). La sociedad descrita por Moro se toma aun hoy como modelo para el diseño de comunidades ficticias abundantes en la literatura, tal como lo señala Gil-Iriarte:

\footnotetext{
En los más de cuatrocientos años transcurridos, utopía ha sido el paraíso soñado, prometido y recobrado; la comunidad humana perfecta donde ensayar la validez práctica de un sinfín de teorías políticas; la trampa de una esperanza irrealizable; utopía ha sido la Ítaca a la que siempre se desea volver, tras haber sido tan sólo intuida en sueños $(2001$, n. p.)
}

Los espacios utópicos son un motivo importante en la literatura latinoamericana contemporánea, siendo algunos ejemplos conocidos Santa Mónica de los Venados, escondida en el corazón de la selva venezolana en la novela de Alejo Carpentier Los pasos perdidos (1953), el Macondo perdido en la ciénaga del Caribe colombiano en Cien años de soledad (1967) de Gabriel García Márquez, y más recientemente Waslala (1996), oculta en la selva de Faguas, en la novela del mismo nombre de la nicaragüense Gioconda Belli. Las tres novelas exploran la búsqueda del "lugar feliz" y siguen a un individuo en su viaje al encuentro de este lugar. Sin embargo, las tres novelas terminan con el fracaso del espacio utópico ya que la utopía no se materializa y termina con la destrucción de la armonía sobre la cual las comunidades fueron fundadas. Al contrario de las otras dos novelas, Waslala sí ofrece propuestas alternativas a la utopía masculina alineadas de acuerdo a una visión feminista.

Este ensayo explora la propuesta feminista que ofrece Belli en relación con la posibilidad de la existencia de una sociedad justa e igualitaria en el contexto de un futuro próximo y familiar. Según esta lectura, la propuesta de Belli se fundamenta en situar a las mujeres a las riendas del poder político como única manera de mantener el orden social. ${ }^{1}$ El modelo matriarcal que se desprende de esta lectura tiene como base el mito de las amazonas, con las cuales se establecen claros paralelos en relación con varios de los personajes femeninos de la novela. En particular, se analizan las características míticas conectadas con las amazonas de la protagonista Melisandra, su abuela doña María, la líder de la ciudad-basurero Engracia, y por fin su madre, que ha quedado como cuidadora y archivadora de la utopía y sus crónicas. Estas mujeres, de manera secuencial, ofrecen a Melisandra enseñanza práctica y guía espiritual, cumplen las funciones de 
madres y de iniciadoras en el liderazgo social y político. Así contribuyen a la formación de una nueva sociedad basada en la justicia social, pero no en una comunidad aislada, sino a través de la transformación de la sociedad ya existente de la que todos pueden -y deben participar, una nueva sociedad en la que Melisandra tendrá un papel protagónico.

La abundancia de novelas que describen la tensión entre espacios utópicos imaginarios y la sociedad distópica real a la que ofrecen una alternativa resalta la importancia del utopismo como concepto crítico fundamental en la lectura de estos textos. El filósofo alemán Ernst Bloch explica que la tradición utópica se nutre de arquetipos de tierras paradisiacas y sociedades ideales, señalando que la imposibilidad de alcanzar esas tierras es precisamente lo que confirma su existencia, en lo que él nombra "esperanza geográfica" (1986, p. 747). Lucy Sargisson usa el término "utopismo" como "an umbrella term referring to a way of seeing and approaching the world and to subsequent ways of representing what is perceived of the world" (1996, p. 1). Sargisson rechaza la definición comúnmente aceptada de utopía como un lugar, estado o condición idealmente perfecto en cuanto a política, leyes, costumbres y condiciones, y explica que esta descripción no se ajusta al utopismo feminista contemporáneo, así como tampoco a muchas utopías históricas. Los proyectos utópicos que asumen la imagen de un futuro idílico y perfecto en todos los sentidos con frecuencia no contienen planes detallados del funcionamiento y logro de semejante patrón. Sargisson promueve una forma de utopismo conectado y contextualizado dentro de los debates sobre la construcción de significado. En este sentido, propone que el feminismo contemporáneo proporciona un contexto desde el que se puede avanzar una nueva concepción del utopismo: "Debates concerning equality and difference, the construction of meaning through language, and the construction of subjectivity, it is argued, provide a backdrop to this new approach to utopianism" (1996, p. 3).

Por otro lado, la obra de Belli ha recibido con frecuencia una lectura feminista. José María Mantero, en un artículo sobre el poemario de Belli Mi íntima multitud explica que "la crítica en torno a la obra de Belli se ha centrado principalmente en la representación de la mujer en sus obras narrativas, particularmente su enfoque "clásico" feminista, la reivindicación del cuerpo femenino, y de la representación de la mujer como sujeto de la historia" (2011, p. 33), señalando además que en sus novelas y en toda su producción poética, Belli "desarrolla una literatura personal comprometida con la identidad de la mujer y con la actualidad de su patria" (2011, p. 33). La visión feminista de Belli se realiza en Waslala con la inclusión de personajes femeninos centrales, no marginales a la acción, mujeres fuertes e independientes que son agentes de cambio y en control de su vida y su destino. En particular, la novela se nutre del mito griego de las amazonas, que en su origen se concibe como una sociedad distópica de mujeres monstruosas que amenazan el orden jerárquico de la sociedad patriarcal, ya que viven en comunidades donde las mujeres tienen todo el poder y los hombres cumplen simplemente una función procreadora. Para una sociedad como la griega para la que la guerra es una actividad exclusivamente masculina, estas mujeres guerreras cuestionan el estatus y la superioridad del hombre, así como la prerrogativa del hombre de dominar y controlar a la mujer en una sociedad estrictamente patriarcal falocéntrica. La crítica feminista ha explorado la situación de la mujer como sujeto silenciado quien, para hablar debe usar un lenguaje que no le pertenece ya que es generado y controlado por el hombre, un proceso que Luce Irigaray y Hélène Cixous han dado en llamar "falogocentrismo". En el contexto colonial, la mujer se convierte en un sujeto doblemente subalterno, tal como señala Gayatri Spivak, quien se pregunta "With what voiceconsciousness can the subaltern speak?" $\left(1988\right.$, p. 285). ${ }^{2}$ 
La exploración europea del continente americano dio pie a imaginar la posibilidad de encontrar la perfecta utopía, una sociedad cerrada y protegida de la contaminación del mundo externo. La Utopía de Moro se nutre de esos sueños del momento, ya que El Dorado, Manoa, la Fuente de la Eterna Juventud tienen como base la búsqueda del "buen lugar" en los territorios americanos. Beatriz Pastor explica el periodo del descubrimiento y la Conquista como un periodo "rico en formulaciones de la armonía imposible" (1996, p. 12) porque "el descubrimiento de América trajo consigo una reactivación vertiginosa de los componentes utópicos de la tradición occidental" (1996, p. 23) donde era posible toparse con la encarnación de los mitos griegos que aun circulaban en el imaginario popular de exploradores y cronistas y que las nuevas reformulaciones de la época como la de Tomás Moro ayudaron a afianzar. En Waslala los viajeros que llegan del mundo occidental resaltan el hecho de que ante la mirada europea, la naturaleza americana ${ }^{3}$ se ofrece como un mundo de posibilidades inexploradas, pero ante todo la posibilidad de volver al origen, al jardín edénico:

\footnotetext{
Le parecían siempre los últimos: los que se habían quedado rezagados en las expediciones a El Dorado o a las fabulosas minas de oro en California: seres de miradas afiebradas que transitaban el río como si viajaran hacia el fin del mundo, con los mismos ojos de asombro que habían tenido los conquistadores españoles o los piratas ingleses deslumbrados ante los árboles gigantes, la lujuria de colores, los pájaros deslizándose en el aire, altos y soberbios (Belli, 2006, p. 18)
}

Otros mitos que resurgen en el continente americano después de la llegada de los europeos apuntan también al espacio utópico pero incorporan elementos que representan una amenaza a la dominación masculina y al patriarcado, convirtiéndolos en espacios distópicos por la perspectiva masculina con que se observan. Tal es el caso de las Amazonas, el pueblo de mujeres guerreras de la mitología griega, organizadas en sociedades matriarcales en que los hombres cumplen una función procreadora pero ocupan un lugar secundario o nulo en la estructura social, y que los exploradores imaginaron y re-situaron en la gran selva americana, dándole su nombre al río más caudaloso del mundo. El mito de las amazonas ejerció tal poder que Francisco de Orellana, durante su viaje en busca de El Dorado, creyó ser atacado por un grupo de mujeres cazadoras mientras remontaba un río que dio en llamar el Amazonas, que ahora también da nombre a la gran región selvática y salvaje que rodea el río y que ocupa mucho del territorio de Brasil y otros países del sur de América. Michael Wood sitúa este episodio en la confluencia de los ríos Napo y Marañón, señalando que las historias de mujeres guerreras aparecen en varias crónicas de la conquista, y el mismo Colón describe un episodio similar. En este caso, el padre Carvajal, que llevaba el diario de viaje de Orellana, insiste en que vieron a estas mujeres e incluso lucharon contra ellas (2006, p. 209).

Según la mitología griega, las amazonas eran un pueblo de solo mujeres descendientes de Ares, dios de la guerra y de la ninfa Harmonía. Su origen mítico apunta ya a la tensión entre el impulso guerrero distópico y la búsqueda utópica que tiene como noción central la armonía social. En el gobierno de esta sociedad no interviene ningún hombre, y como jefe tienen una reina. La presencia de los hombres solo era permitida para desempeñar trabajos de servidumbre. ${ }^{4}$ Para perpetuar la raza se unían con extranjeros, pero sólo conservaban a las niñas. Si nacían varones, se cuenta en algunas versiones, que los mutilaban dejándolos ciegos y cojos, mientras que otras fuentes indican que los mataban, tal como señala Sebastián Martínez en "Amazonas, mito y leyenda". Por decreto, a todas las niñas les cortaban un seno, para facilitarles el uso del arco y el manejo de la lanza. De esta costumbre proviene su nombre 'amazonas' del término griego que significa 'las que no tienen seno'. 
El título de la novela Waslala de Gioconda Belli se refiere al nombre de una comunidad secreta (y para muchos legendaria) escondida en la selva del país ficcional Faguas (que como en sus otras novelas es la contrapartida ficcional de Nicaragua) en América Central, (en la parte del país cerca de la costa del Atlántico, tradicionalmente una región aislada, apartada, pobre, y culturalmente distinta al resto del país). Según las muchas historias que circulan por Faguas, Waslala había sido fundada sobre los principios de igualdad, armonía y justicia, y necesariamente separada del resto del mundo para la preservación de esos principios. La novela se abre con la llegada de unos viajeros a la hacienda del río donde vive la joven protagonista Melisandra con su abuelo, el hombre que fue uno de los fundadores de la comunidad utópica de Waslala, desde entonces exiliado en esta hacienda en la selva de Faguas, y fuente de muchas de las historias que mantienen viva a esta comunidad en el imaginario fagüense y en especial en la mente de su nieta, quien ya ha decidido salir en su busca. La conexión con la obra de Moro se produce al principio de la novela con una referencia explícita, cuando el dueño de la hacienda, Don José, ${ }^{5}$ reacciona al nombre de uno de los viajeros: "Qué cosas, ¿verdad? Se llama Raphael. El de Tomás Moro, el que descubre la isla llamada Utopía, se llamaba Raphael también” (2006, p. 36). Gil-Iriarte, en el artículo "Waslala: reescritura femenina de la utopía", explica que:

\begin{abstract}
Teniendo en cuenta el texto de Tomás Moro y las similitudes con Waslala, especialmente en los capítulos dedicados al encuentro del lugar, se pueden señalar una serie de características que son comunes a los relatos utópicos. Ante todo se trata de una concepción de la sociedad y el mundo teórica y difícil de llevar a la práctica (hasta cierto punto irrealizable) que tiene una visión optimista y esperanzadora del ser humano (2001, n. p.)
\end{abstract}

La hacienda junto al río es un lugar aislado y solitario, y la llegada de los viajeros es un acontecimiento importante, ya que solo ocurre una vez al año cada octubre. A pesar de que se les llama "los contrabandistas" (2006, p. 17), el grupo está compuesto por individuos muy diferentes con planes y agendas bien diferenciadas: además de Raphael, el periodista americano que investiga una nueva droga sintética llamada filina, llega Hermann, un alemán traficante de oro; Morris, un científico americano con un brazo metálico "provisto de instrumentos que le servían para su trabajo" (2006, p. 24); Maclovio, un argentino que trafica en armas y drogas; y dos mujeres holandesas sin motivo claro para el viaje. A ellos se sumará Melisandra, que ha decidido que va a emprender el viaje en busca de sus padres, que la abandonaron a los tres años a cambio del sueño de Waslala.

El abuelo soñador, idealista e intelectual filosofa con los viajeros, ofreciendo una visión histórica del país Faguas que supone una denuncia de la globalización, la explotación y el abandono en que los países ricos han sumido a aquellas regiones de las que extraen todo lo aprovechable y luego dejan a la deriva, realzando desde el inicio de la novela el ambiente altamente distópico en el que se desarrolla la acción, y apuntando a la necesidad de crear una sociedad alternativa con características utópicas:

\footnotetext{
No le era posible definir con exactitud el momento en que el desarrollo de Faguas empezó a involucionar y el país inició su retorno a la Edad Media, perdiendo sus contornos de nación y pasando a ser, en los mapas, una simple masa geográfica como lo eran antes las selvas del Amazonas y, ahora, vastas regiones de África, Asia, la América del Sur, el Caribe: manchas verdes sin rasgos, sin indicación de ciudades, regiones aisladas, cortadas del desarrollo, la civilización, la técnica, reducidas a selvas, reservas forestales, a función de pulmón y basurero del mundo desarrollado que las explotó para sumirlas después en el olvido, en la miseria, condenándolas al ostracismo, a la categoría de terras incógnitas, malditas, tierras de guerra y epidemias adonde últimamente solo llegaban los contrabandistas (Belli, 2006, p. 19)
}

La tensión entre la utopía y la distopía es evidente en esta descripción. Faguas aparece descrita aquí como el lugar aislado, separado de la civilización y cerrado, la tierra desconocida 
y oculta que representa una vuelta a las raíces, al inicio de la historia, que contiene muchos de los elementos descritos por Moro en su Utopía. Ana Patricia Rodríguez explica que "overtaken by its own nature, contamination and violence, and its dystopic future, Faguas is the site and symbol of the complete devastation and posible regeneration of Central America" (2009, p. 217), intuyendo también la estrecha conexión entre destrucción y renacimiento, apocalipsis como única posibilidad de génesis, final que da pie a un nuevo principio, y por supuesto, el vínculo indisoluble entre espacio utópico y distópico. La tensión entre utopía y distopía se revela de nuevo en la visión de los hermanos Espada, que han creado un imperio aprovechando los muchos conflictos bélicos que han asolado al país durante años:

\footnotetext{
Antes las guerras se ganaban o se perdían -dijo Espada-. Ahora es un asunto de continuidad, de conservar lo ganado. Ya no hay ni amigos ni enemigos claramente definidos. La información es primordial. La estrategia es más compleja. Se combate en muchos frentes al mismo tiempo y por razones distintas. Los contendientes de hoy pueden ser los aliados de mañana. "Guerra fluida" lo llamo yo. Requiere de mucha memoria. (...) ¿Qué otra cosa es Waslala, si es que existe, si no una comunidad soberana, ubicada en un vacío social? (Belli, 2006, p. 169)
}

La hacienda está compuesta por varias familias que comparten el trabajo y el producto del trabajo de forma comunitaria. La comunidad fue creada por la difunta doña María, la abuela de Melisandra y esposa de don José, que construyó un refugio para dar protección y comida a las víctimas de una epidemia, mientras su esposo exploraba las posibilidades filosóficas e intelectuales de una sociedad ideal. Paradójicamente, la hacienda contiene varios elementos característicos de las comunidades utópicas que don José estudiaba en la literatura:

\footnotetext{
El trabajo estaba dividido entre las distintas familias a quienes la abuela ofreció refugio luego de una plaga de paludismo que diezmó las aldeas vecinas. Con mínimos recursos e incansable trabajo, la tierra producía vegetales y granos suficientes para el autoconsumo de sus habitantes. Contaban también con una granja de pollos y cerdos y un pequeño hato de ganado para carne y leche (Belli, 2006, p. 47)
}

Sin embargo, el impulso de don José y de otros idealistas como Ernesto, "un poeta callado, sabio, con profundos conocimientos de la física y del cosmos" (Belli, 2006, p. 52) fue recrear ese espacio de forma artificial, para así tener control de las circunstancias y el desarrollo del ambiente. Se aprecia en este intento un instinto de depuración, de sanear, de limpiar, no a nivel social, sino a nivel genético. Este grupo intenta reproducir de forma intencional y sostenida el mismo proceso involutivo que está ocurriendo a su alrededor de forma espontánea y natural. Mientras que la ciencia se asocia normalmente con el proceso evolutivo, en este caso se relaciona con la involución, la vuelta a un origen, a un núcleo original, al principio de la vida, llegar al paraíso terrenal, al jardín del Edén, para empezar de nuevo desde ese momento primigenio de creación y recrear un ser humano puro y libre de todo mal:

\footnotetext{
Provistos de cuanta literatura utopista pudimos acumular, nos dimos a la tarea de delinear modelos y desarrollar incontables simulaciones especulando con esta o aquella alternativa. [...] "Necesitamos la isla para construir la Utopía -decía [Ernesto]-. Hay que crear el núcleo original, descontaminarlo a través de varias generaciones hasta que solo lo conformen hombres y mujeres que nunca hayan conocido la ambición, el poder, la avaricia, el mal. Se trata de construir la célula, la partícula, el primer organismo vivo (Belli, 2006, p. 53)
}

El mismo Ernesto $^{6}$ que conceptualiza la necesidad de fundar una utopía en este contexto histórico describe un espacio geográfico en el norte del país de gran belleza natural -y sobrenatural. Durante su estancia allí tiene una visión profética de la sociedad que debe construir: "Durante una de las noches que él pernoctó allí soñó con una ciudad plateada. Su nombre, "Waslala", aparecía sobre los troncos viejos y monumentales de los ceibos" (Belli, 
2006, pp. 53-54). ${ }^{7}$ Al igual que el Solentiname de Ernesto Cardenal, la comunidad de Waslala se puede encontrar en localización real en Nicaragua, con conexiones políticas a la revolución sandinista claras puesto que, como apunta Ana Patricia Rodríguez, Waslala "alludes to a town with the same name located in north central Nicaragua, which was a Sandinista stronghold and site of a communitarian project in the 1970s and 1980s" (2009, p. 217). El pueblo cobró de nuevo relevancia en octubre de 1990 cuando ocurrieron enfrentamientos entre campesinos sandinistas y ex contras en relación a la reforma agraria y el derecho a la tierra, que dejó varios muertos. ${ }^{8}$

En la novela, sin embargo, Waslala ocupa un espacio especial, del que se puede entrar y salir solo cuando se dan ciertas condiciones y cuando uno está en un estado de gracia particular, ya que los fundadores "sin percatarse, establecieron la comunidad en un sitio donde había una ranura en el tiempo, algo así como un traslapo en la curvatura del espacio. Waslala quedó existiendo en un interregno, tras una especie de puerta invisible" (Belli, 2006, p. 106). La joven protagonista Melisandra se cría con estas historias del abuelo, en la hacienda a orillas del río en la selva de Faguas, rodeada de la nostalgia de Waslala y extrañando la ausencia de sus padres, desaparecidos en la selva años atrás cuando ella era una niña de tres años, idos en busca de esta sociedad que el abuelo fundara. Melisandra ha decidido que sus padres viven y que están todavía en Waslala y quiere ir en su busca. Así emprende el viaje río arriba y selva adentro que la lleva a encontrar no solo a Waslala y a su madre, sino también a ella misma.

La presencia de mujeres con conexiones al mito de las amazonas es prevalente por toda la novela, y aparece de forma clara en el personaje de Melisandra, quien es una mujer joven, bella, fuerte e independiente. El personaje de Melisandra es transgresor de los papeles de género en la sociedad patriarcal, y aparece con características típicamente asociadas con los hombres: adopta un papel activo en sus relaciones sexuales con Joaquín y toma la iniciativa con Raphael; aparece por primera vez en la novela realizando trabajos normalmente considerados masculinos (reparando el tejado de la casa y supervisando a los trabajadores de la hacienda). Su nombre está en consonancia con las características de su personaje, ya que en su origen alemán antiguo Melisandra significa "fuerza animal". En griego la melisa se refiere a las abejas y la miel, mientras que el sufijo -andra recuerda a la palabra griega para la virilidad, trayendo connotaciones a la vez femeninas y masculinas en el nombre. ${ }^{9}$ Valeria Lafita Fernández destaca que "la relación de Melisandra con el cuerpo y la sensualidad es natural, sin culpas ni planteamientos. Su transgresión pasa por otra parte, por la apropiación de una acción tradicionalmente masculina: el viaje como una forma de autoconocimiento y búsqueda de la propia identidad" (2009, p. 8). El papel que juega la figura de la madre en las novelas de Gioconda Belli es importantísimo, como destaca Lafita Fernández, ya que con frecuencia "son las madres las encargadas de transmitir las normas sociales, de señalarles las transgresiones, de conectarlas con esa realidad aceptada como única y válida. Las madres encarnan la voz de la tradición y del estereotipo de mujer construido a partir de la mirada patriarcal, que acepta el deber y no lo cuestiona" (2009, p. 10). En las novelas de Belli, sin embargo, las protagonistas

\footnotetext{
son desestabilizadoras, quebrantan el orden moral, social y político en el que han nacido y proyectan una nueva mujer. Son mujeres subversivas, pero no sólo porque quieran romper con el estereotipo que se les ha impuesto o entren en las esferas que tradicionalmente se les ha asignado a los hombres, sino porque la resistencia, la rebeldía, la transgresión, la ruptura tiene lugar en los mismos espacios periféricos que se han visto obligadas a ocupar y porque hay una revalorización de los atributos femeninos. (2009, p. 5)
}

En el caso de Waslala no hay una sino tres mujeres que comparten este papel de guía, maestra y modelo de Melisandra. Estas mujeres aparecen en la vida de Melisandra por separado y en momentos clave de evolución personal, y proveen a Melisandra con enseñanzas 
que la ayudan a alcanzar su próxima meta y la guían en su proceso de autoconocimiento. La abuela primero (en la hacienda junto al río), Engracia después (en la ciudad-basurero de Cineria), y por fin la madre (en Waslala) comparten características amazónicas con Melisandra, formando entre las cuatro una comunidad imaginada de mujeres fuertes que adoptan posiciones de liderazgo de forma natural y espontánea y contribuyen a crear comunidades basadas en la justicia social, haciendo frente al caos distópico creado por los hombres a su alrededor.

En la ausencia de sus padres, son los abuelos quienes crían a Melisandra. Mientras el abuelo se encarga del aspecto intelectual e idealista de su educación, de su abuela aprende la iniciativa y el liderazgo que le permite ocuparse de las faenas de la hacienda y la supervisión de las labores del campo. Su abuelo don José destaca la conexión entre ellas cuando describe a la abuela como la mujer fuerte e independiente que era capaz de cazar a un jaguar ella sola, asociándola así con las características propias de las amazonas, y a la vez conectando a Melisandra misma con estas:

\footnotetext{
Ah, hijita, hijita. Me recordás tanto a tu abuela. ¿Te conté de la vez que cazó un jaguar cerca de aquí? Ella sola. Amarró el animal al jeep y lo arrastró por el camino. Me parece que la estoy viendo aparecer de madrugada; roja como una leona, los chavalos siguiéndola para ver el jaguar muerto. Con los dientes le hizo un collar a tu mamá. ¡Qué mujeres, ustedes! ¡Qué va a poder hacer uno! (Belli, 2006, pp. 40-41)
}

Melisandra ha decidido que va a emprender viaje hacia el norte y parte con el resto de los viajeros en bongo río arriba y al otro lado del gran lago hasta llegar a Las Luces, "una ciudad de lodo y aluminio" (Belli, 2006, p. 99) donde Raphael observa fascinado el ir y venir de la gente en una escena que a él, como extranjero, le resulta extraña y asombrosa: "Raphael vio también gente en bicicleta y otros que empujaban carretillas de supermercado destartaladas que, según le explicó Morris, eran parte del botín que llegaba a Faguas en los contenedores de basura" (2006, p. 144). En esta corta escala en Las Luces tanto los viajeros como los lectores oyen las leyendas que aun circulan de Waslala, y también se familiarizan con lo que van a encontrar en Cineria, una ciudad dominada por dos fuerzas opuestas y en conflicto, cada una dominando un territorio bien delimitado: por un lado están los hermanos Espada, que desde su fortín dirigen y controlan el tráfico de armas y de drogas entre Faguas y los países del primer mundo. Por otro lado está Engracia, la enorme mujer que "maneja la distribución de lo que viene en los contenedores de basura" (2006, p. 105).

Cineria es la ciudad-basurero a donde van a parar todos los desechos -electrónicos, mecánicos y químicos- del primer mundo, un lugar que según Laura Barbas-Rhoden subraya la crítica a la globalización y a la brecha abierta entre las regiones ricas y pobres del mundo (2005, p. 12). Cineria es un espacio de destrucción y desecho, pero también de creación y de regeneración, donde se pueden encontrar los desechos del primer mundo que llegan en los contenedores de basura. En este "cruce entre hábitat humano y depósito de chatarra" (Belli, 2006, p. 99), "restos de cuanto objeto cupiera en la imaginación yacían apilados en grandes montañas, componiendo esculturas caprichosas, entes de otro mundo" (2006, p. 133) ya que "no hay desarrollo sin desperdicio" (2006, p. 136). Estos desechos del consumo desaforado del primer mundo, "lavadoras, secadoras, refrigeradores, televisores, sillas de ruedas, toneladas de vidrio escapadas del reciclaje, mobiliario de oficina, corrocerías, purificadores de aire, candelabros, lámparas" (2006, p. 134) serán cuidadosamente examinados, clasificados, catalogados, separados, reparados y puestos otra vez en circulación para una nueva vida en su nuevo ambiente. En palabras de Ana Patricia Rodríguez, "Cineria is the metaphoric phoenix of Central America" (2009, p. 217). 
Engracia es la enorme mujer que preside sobre personas y chatarra en Cineria. A su llegada, Morris y Engracia reinician su relación de viejos amantes y amigos. Ella es el personaje que más directamente se emparenta con las amazonas, siendo descrita como tal repetidamente bajo la mirada de Morris:

\footnotetext{
Engracia estaba totalmente desnuda. Su cuerpo ya no era joven pero seguía siendo fuerte e imponente. Tenía piernas delgadas y altas que sostenían las caderas angostas y unos pechos grandes en descenso que ella movía de un lado al otro con el mismo desenfado con que sacudía su larga cabellera. A Morris siempre le pareció una amazona descarriada. Bien podía imaginarla desnuda y morena con el pecho amputado para cargar mejor el arco y las flechas (Belli, 2006, p. 130)
}

No solo la apariencia encaja con los seres míticos, también el comportamiento y la actitud transgresora corresponden a tal. En sus encuentros sexuales, Engracia es insaciable y apasionada, pero "se saciaba y luego volvía otra vez a su estado de amazona indiferente a los placeres de la carne" (Belli, 2006, p. 131). Inmediatamente Engracia se convierte en protectora de Melisandra, ayudándola en su viaje de búsqueda de Waslala, y guiándola en la peligrosa negociación con los Espada para poder efectuar el viaje de forma segura a través de los territorios que los hermanos controlan.

Mientras tanto, la aparentemente inocua chatarra resulta letal cuando un cargamento incluye un cilindro lleno de un polvo azul fosforescente que el científico Morris inmediatamente identifica como parte de "una de las máquinas que se habían utilizado para irradiar enfermos de cáncer antes de que la recién descubierta terapia genética permitiera aislar y neutralizar el gen de los recién nacidos" (Belli, 2006, p. 186). Para cuando Morris identifica el objeto, ya es demasiado tarde, ya que Engracia y varios de los muchachos que trabajan en el basurero separando y clasificando la chatarra se han untado el cuerpo pensando que es solamente pintura fosforescente, pero el polvo azul es en realidad cesio 137, un isótopo radiactivo del que han recibido una dosis letal que les causará vómitos, fiebre, dolor de cabeza, quemaduras, y después de unos días, la muerte.

La proximidad de la muerte inevitable a causa del envenenamiento por el cesio 137 inspira a Engracia -junto con los chicos también envenenados- a lanzar un ataque por sorpresa contra el cuartel de los Espada, para acabar con su imperio de terror de una vez por todas. Con las pocas fuerzas que le quedan, Engracia se cubre todo el cuerpo con el polvo azul, para que durante el ataque el cuartel, parezca que están siendo atacados por fantasmas Wiwilí, seres de la mitología maya. Una vez más, Engracia se compara con una amazona: "Se vio bella como una amazona mítica, como el imponente mascarón de proa de algún navío descarriado y fantasmagórico" (Belli, 2006, p. 255). Como una amazona, Engracia no abandona la lucha y no se rinde ante la proximidad de la muerte, prefiriendo morir en la batalla antes que entregarse al enemigo. El grupo liderado por Engracia consigue su objetivo de hacer explotar una bomba en el cuartel de los hermanos Espada, con lo que consiguen la liberación de la gente de Faguas del control dictatorial que los hermanos tenían sobre el país y sus habitantes. Melisandra, que había sido secuestrada y estaba prisionera en el sótano del fortín, es liberada por Raphael y Maclovio aprovechando la confusión creada por la llegada de los fantasmas azules.

El viaje de Melisandra hacia Waslala continúa con Raphael como compañero de viaje. En el proceso, pasan por Timbú, una ciudad poblada por huérfanos que han decidido crear una comunidad de acogida para las víctimas humanas de la guerra; allí se esconden las plantaciones de filina que les permiten sobrevivir y mantenerse en paz con los hermanos Espada; allí también se encuentran las dos mujeres holandesas, Krista y Vera, cuyo viaje 
tenía como propósito adoptar un bebé huérfano en Timbú. De allí continúan viaje por la selva, acompañados del loro de Engracia que ahora es la responsabilidad de Melisandra. En el interior de la selva se encuentran con Hermann, que tiene una casa en un pueblo situado en unas antiguas minas de oro y que se va a encargar de guiarlos en el siguiente trayecto del viaje. Mientras pernoctan en el campamento improvisado, Melisandra se despierta y no encuentra al loro. Creyendo verlo, se adentra en la selva hasta que le parece ver una reverberación que señala la "ranura en el tiempo" (Belli, 2006, p. 324) en que Waslala existe. El loro de Engracia le sirve de guía a Melisandra para encontrar la entrada de Waslala:

A mitad de la carrera reconoció el instante en que su cuerpo se aligeró y sus piernas rotando rítmicas
alcanzaron el impulso, la aceleración que convertía el correr en una deliciosa sensación de levedad. Cruzó
la reverberación, que se disolvió como un espejismo al acercársele y siguió corriendo en dirección al
árbol donde creyó ver al loro (Belli, 2006, p. 309)

Cuando llega a Waslala, Melisandra descubre que el pueblo parece estar deshabitado y los interiores de las casas "tenían un velado aire de abandono y decrepitud" (Belli, 2006, p. 315). Solo una persona queda en el pueblo, y es su madre. La madre de Melisandra presenta características amazónicas tanto por ser la guardiana de la comunidad y de sus anales, así como por su papel de líder en la formación colectiva de la comunidad. Ella le cuenta la historia de la fundación de Waslala, como llegaron ella y el padre allí, incluyendo el terrible trauma de la violación de ella y el asesinato cometido por él en defensa propia. La madre explica cómo el pueblo fue creciendo y organizándose para después decaer por dos motivos: conflictos con el manejo del poder, y la imposibilidad de procrear. Waslala, creada sobre la base teórica de crear "la célula, la partícula, el primer organismo vivo" (2006, p. 53) que debe "prescindir por completo de la tentación de multiplicarse" (2006, p. 53) resulta ser una sociedad estéril que no puede multiplicarse y que por lo tanto está condenada a desaparecer en el curso de una generación. ${ }^{10}$

La paradoja se extiende a la forma de administrar el poder: la sociedad fundada por "hombres profundamente buenos, profundamente nobles" (Belli, 2006, p. 285) forman una asamblea en la que todos los miembros de la comunidad tienen iguales derechos y voz. El caos que se crea con tantas voces e ideas contradictorias condena a los poetas fundadores a sentirse "cada vez más arrinconados y atacados" (2006, p. 285) hasta que se toma la decisión de disolver la asamblea, que se había convertido en "un pequeño monstruo, una dictadora arbitraria, impulsiva, inconsciente" (2006, p. 285) y darle a los poetas "una autoridad casi total” (2006, p. 285). Lo que comenzó como una comunidad fraternal e igualitaria se convirtió en una autocracia.

Como Santa Mónica de los Venados en Los pasos perdidos y como Macondo en Cien años de soledad, Waslala se descubre por fin como una falsa utopía, la derrota del concepto de utopía concebida según la definición tradicional. Pero Melisandra no sale de Waslala con las manos vacías. Al contrario, armada con su nuevo entendimiento de las razones del fracaso de la utopía y cargada con los anales de Waslala, que documentan todo el proceso de construcción y el deterioro del proyecto utópico, Melisandra se despide de su madre y atraviesa la reverberación para volver a la selva de Faguas. Melisandra entiende que "la razón de ser de Waslala era ser Waslala, la utopía, el lugar que no era, que no podía ser el tiempo y el espacio habitual..." (Belli, 2006, p. 331), y cuando cruza la reverberación, no deja Waslala sino que la lleva consigo, porque tal como propone Cecil Zinani, "Waslala existe no interior de cada um, tanto como recuperaçao do pasado como projeçao do futuro, ensejando imensas posibilidades de realizaçao para o ser humano" (2004, p. 126). La novela se cierra presentando a Melisandra 
en su nuevo papel de líder de la reconstrucción de Faguas y de administradora de los anales de Waslala, que servirán como modelo de la nueva sociedad fagüense:

\begin{abstract}
$\mathrm{Ni}$ [Raphael], ni quienes presenciaron el inusitado espectáculo, olvidarían la escena: la muchacha alumbrada por viejos faros de barco y de estadio, hablando apasionadamente de ese lugar ignoto y feliz, mientras a su alrededor se apilaban en desorden los desechos de las grandes urbes, cuanto el ser humano había creado buscando siempre la elusiva y efímera felicidad (Belli, 2006, p. 339)
\end{abstract}

Belli ofrece un final optimista y esperanzador, que contempla la posibilidad de no uno, sino varias posibilidades de "lugar feliz": los huérfanos de Timbú repoblarán Waslala, devolviéndole la fertilidad; los ciudadanos de Faguas se unirán en la tarea común de reconstruir el país como una sociedad más justa (después de la dictadura de los Espada), y bajo la dirección de Melisandra como nueva líder, guiados intelectualmente por los anales de Waslala; y en un toque irónico, surgirá un nuevo comercio de artesanías fabricadas con los materiales de desecho que llegan en los contenedores, y que ahora van a volver al primer mundo como símbolos del renacimiento, la regeneración, la creatividad y la energía de los fagüenses.

La propuesta social de Belli reformula el ideal utópico al poner la construcción de comunidad en el centro y a las mujeres al frente del proyecto nacional. Mientras que la utopía, tal como fue concebida por los griegos y más tarde por Tomás Moro, es un espacio cerrado, puro y libre de contaminación externa, los varios espacios que nos presenta Belli construyen la utopía en la sociedad real, abierta e impura, y llevan al frente una mujer. Este espacio inclusivo y abierto reclama el mito de las amazonas no como el espacio distópico que imaginaron los griegos y re-inventaron los cronistas del renacimiento, sino como una comunidad de inclusión y justicia humana por medio de la lucha social y la igualdad de género.

\title{
Notas
}

1. En su novela El país de las mujeres (2013), Belli explora los conflictos y las oportunidades que se darían en un país (en su caso de nuevo Faguas) en que un partido compuesto exclusivamente por mujeres, PIE (Partido de Izquierda Erótica) llega al poder e impone cambios radicales en la política del país, con la presidenta Viviana Sansón al frente.

2. Numerosos críticos han analizado la relación entre voz y poder con relación a sujetos socialmente marginados. Algunas lecturas feministas esenciales son las aportadas por Hélène Cisoux y Luce Irigaray, y en particular su uso del término "falogocéntrico” para hablar de la conexión entre el lenguaje y lo masculino.

3. En el prólogo a El reino de este mundo Alejo Carpentier explora el concepto de lo real-maravilloso, que parte de la percepción de lo maravilloso que "surge de una inesperada alteración de la realidad”. García Márquez, por su parte, en su discurso ante la la Academia Sueca, después de recibir el premio Nóbel, también se refiere a la "realidad desmesurada" que debe medirse en una escala diferente a la europea.

4. Este aspecto de la sociedad de las amazonas recuerda a la de las abejas, por su estructura estrictamente jerárquica, en la que la reina ocupa el lugar más alto, toda la producción y cuidado de la colmena es encomendado a las abejas obreras, y los zánganos cumplen simplemente la función procreadora.

5. La autora indica en una nota al final de la novela que el personaje de don José y su esposa doña María (los abuelos de Melisandra) están "basados en dos seres extraordinarios que vivieron sus vidas al lado del río San Juan en Nicaragua: José Coronel Utrecho y María Kautz” (Belli, 2006, p. 341). Don José fue uno de los poetas nicaragüenses más reconocidos e influyentes en la siguiente generación de escritores. Para Belli, su novela Waslala es una forma de reconocer su deuda intelectual al "Poeta Coronel" y su mujer.

6. No es difícil imaginar al gran poeta nicaragüense Ernesto Cardenal como inspiración para este personaje, y por ende la inspiración de Waslala en Solentiname, la comunidad creada por Cardenal en la isla del lago Nicaragua. 
7. Esta visión conecta a nivel narrativo con la revelación de otro espacio utópico bien conocido, el de Macondo, a su fundador José Arcadio Buendía, como aquí con Ernesto.

8. La revista Envío documenta este episodio reciente en el artículo "Waslala: Anatomy of a Conflict" en el volumen 112 en noviembre de 1990.

9. Por otra parte, su nombre es muy similar a Melisendra, personaje del Quijote que aparece en el capítulo 26 de la segunda parte, en que un muchacho con un retablo de títeres cuenta la historia que "trata de la libertad que dio el señor don Gaiferos a su esposa Melisendra, que estaba cautiva en España, en poder de moros" (Cervantes-Saavedra, 2004, p. 751).

10. La idea de Melisandra para regenerar Waslala es enviar a los habitantes de Timbú a repoblar Waslala (Belli, 2006, p. 334).

\section{Bibliografía}

Barbas-Rhoden, L. (2005). Greening Central American Literature. Interdiciplinary Studies in Literature and Environment. 12-1, 1-17.

Belli, G. (2006). Waslala. Memorial del futuro. Barcelona: Seix Barral.

Bloch, E. (1986). The Principle of Hope. Oxford: Basil Blackwell.

Carpentier, A. (1953). Los pasos perdidos. Madrid: Alfaguara.

Cervantes Saavedra, M. (2004). Don Quijote de la Mancha. Edición IV centenario. Madrid: RAE.

Cixous, H. (1976). The Laugh of the Medusa. Signs. 1 (4), 875-93.

García Márquez, G. (1967). Cien años de soledad. Buenos Aires: Editorial Sudamericana.

Gil-Iriarte, M. L. (2001). Waslala: reescritura femenina de la utopía. Por C. Alemany-Bay, R.

Mataix, J. C. Rovira (Eds.). La isla posible. http://www.cervantesvirtual.com/servlet/

SirveObras/12482280880131519643846/index.htm [Consulta 3 de marzo de 2015].

Irigaray, L. (1985). This Sex Which Is Not One. Ithaca, NY: Cornell University Press.

Lafita-Fernández, V. (2009). Utopía con nombre de mujer. (Tesis doctoral). Universidad de Barcelona.

Mantero, J. M. (2011). Mi íntima multitud de Gioconda Belli y la fragmentación de la utopía. Chasqui. 40 (2), 33-43.

Marin, L. (1993). The Frontiers of Utopia. Critical Inquiry. 19 (3), 397-420.

Martínez, S. (s. f.). Amazonas, mito y leyenda. Revista de Humanidades Sarasuati. http:// www.sarasuati.com/amazonas-mito-y-leyenda/ [Consulta 3 de marzo de 2015].

Pastor, B. (1996). El jardín y el peregrino. Ensayos sobre el pensamiento utópico latinoamericano 1492-1695. Amsterdam: Rodopi.

Real Academia Española. (1992). Diccionario de la lengua española. (21 ed.). Madrid: Espasa-Calpe.

Revista Envío. (1990). Waslala: Anatomy of a Conflict. Envío. 112. http://www.envio.org.ni/ articulo/2641 [Consulta 3 de marzo de 2015].

Rodríguez, A. P. (2009). Dividing the Isthmus. Central American Transnational Histories, Literatures, and Cultures. Austin: University of Texas P.

Sargisson, L. (1996). Contemporary Feminist Utopianism. London: Routledge. 
Spivak, G. (1988). Can the Subaltern Speak? Marxism and the Interpretation of Culture. C. Nelson and L. Grossberg (Eds.) London: Macmillan.

Zinani, C. (2004). Nicaragua e Gioconda Belli: um diálogo possível. Revista de letras. 44 (2), 105-128. 
